\title{
Endoscopic ultrasound-guided, through-the-needle forceps biopsy for diagnosis of pancreatic cystic lesions: a systematic review
}

\section{(이요 $\odot$}

\author{
Authors \\ Institutions \\ 1 Gastroenterology Unit of Hospital Nacional Edgardo \\ Rebagliati Martins, Lima, Peru \\ 2 Universidad Peruana de Ciencias Aplicadas (UPC), \\ Alicante, Spain \\ 3 Gastroenterology Unit of Hospital Universitario del \\ Vinalopo, Elche, Spain \\ 4 Gastroenterology Unit oh Hospital General Universitario \\ de Alicante, Alicante, Spain
}

Edson Guzmán-Calderón ${ }^{1,2}$, Belen Martinez-Moreno ${ }^{3}$, Juan A. Casellas ${ }^{4}$, Enrique de Madaria4, José Ramón Aparicio ${ }^{4}$

submitted 15.1 .2020

accepted after revision 23.3.2020

Bibliography

DOI https://doi.org/10.1055/a-1149-1647 |

Endoscopy International Open 2020; 08: E1123-E1133

(c) Georg Thieme Verlag KG Stuttgart · New York

eISSN 2196-9736

Corresponding author

Gerly Edson Guzmán-Calderón, Prol Manco II - 115

Condominio Villa Marina, Block A, San Miguel, Lima, Perú

edson_guzman@hotmail.com

\section{ABSTRACT}

Background and study aims Pancreatic cystic lesions $(\mathrm{PCL})$, are a heterogeneous group of cystic lesions. Some patients with PCLs have a significantly higher overall risk of pancreatic cancer and the only test that can differentiate benign and malignnat PCL is fine-needle aspiration plus cytological analysis, but its sensitivity is very low. Throughthe-needle direct intracystic biopsy is a technique that allows acquisition of targeted tissue from PCLs and it may im- prove the diagnostic yield for them. The aim of this study was to review articles about endoscopic ultrasound (EUS)guided through-the-needle intracystic biopsy for targeted tissue acquisition and diagnosis of PCLs.

Methods A systematic review of computerized bibliographic databases was carried out for studies of EUS-guided through-the-needle forceps biopsy (EUS-TTNB) of PCLs. The percentages and their $95 \%$ confidence intervals (Cls) were calculated for all the considered endpoints (technical success, adequate specimens, adverse events (AEs), and overall diagnosis).

Results Overall, eight studies with a total of 423 patients were identified. Pooled technical success was $95.6 \%$ of the cases (399/423), (95\% Cl, 93.2\%-97.3\%). Technical failure rate was $5.1 \%$ (24 cases). Frequency of adequate specimens was $82.2 \%$, (95\% Cl, 78.5\%-85.8\%). Adverse events were reported in seven of the eight studies. Forty-two total adverse events were reported $(10.1 \%)$ ( $95 \% \mathrm{Cl}, 7.3 \%-13.6 \%)$. The overall ability to provide a specific diagnosis with EUSTTNB for diagnosis of pancreatic cystic lesions was $74.6 \%$ (313 cases), (95\% Cl: $70.2 \%-78.7 \%)$. The most frequent diagnoses found with EUS-TTNB were mucinous cystic neoplasms (MCN) in 96 cases (30.6\%), IPMN in 80 cases (25.5\%), and serous cystoadenoma neoplasm (SCN) in 48 cases $(15.3 \%)$.

Conclusions Through-the-needle forceps biopsy appears to be effective and safe, with few AE for diagnosis of pancreatic cystic lesions. This technique had acceptable rates of technical and clinical success and an excellent safety profile. TTNB is associated with a high tissue acquisition yield and provided additional diagnostic yield for mucinous pancreatic lesions. TTNB may be a useful adjunctive tool for EUS-guided assessment of PCLs.

\section{Introduction}

Pancreatic cystic lesions (PCL), are a heterogeneous group of cystic lesions which are divided into two groups: first, mucinous lesions, that include intraductal papillary mucinous neoplasms (IPMN) and mucinous cystic neoplasms (MCN); and non-mucinous lesions (NMN), that include: serous cystic neoplasms (SCN), pseudocysts, cystic neuroendocrine tumors, solid pseudopapillary tumors, and cystic pancreatic ductal adenocarcinomas [1-3]. All these lesions have diverse clinical, radiological and pathological features. IPMN is the most common $[4]$. 
Frequent use of high-quality cross-sectional imaging has led to a significant increase in the diagnosis of PCLs, however, clinical decision-making remains limited. Magnetic resonance imaging and magnetic resonance cholangiopancreatography are superior to computed tomography in identifying communication between a PCL and the pancreatic duct, the number of $P C L s$, and presence of a mural nodule [5]. In Spain, a prospective study performed in 298 patients showed that prevalence of unexpected PCLs on endoscopic ultrasound (EUS) is $21.5 \%$, higher than the prevalence estimates in cross-sectional imaging studies [6]. Currently, the management of PCLs relies on the combination of clinical features, cross-sectional imaging and endoscopic ultrasound with or without fine-needle aspiration (FNA) and fluid analysis. Limitations of these tests are low sensitivity (42\%) [7]; carcinoembryonic antigen in the cyst fluid has a sensitivity of $52 \%$ to $79 \%$ [5]. FNA plus cytological analysis is a test that can differentiate benign and malign PCLs, but sensitivity is very low. Most importantly, due to the limited accuracy, new diagnostic tools have been introduced to differentiate benign from precancerous and/or malignant PCLs, including EUS-guided through-the-needle forceps biopsy (EUS-TTNB), cyst fluid molecular studies and EUS-guided needle-based confocal laser endomicroscopy (nCLE). The INDEX study showed that EUS with nCLE identified mucinous PCLs with $98 \%$ sensitivity, $94 \%$ specificity, and $97 \%$ accuracy. nCLE was more accurate in classifying mucinous vs nonmucinous cysts than the standard method [8].

TTNB was first performed by Aparicio et al. in 2010 [9], in an attempt to improve the diagnostic yield of PCLs. In this report, biopsy forceps and a SpyGlass fiber optic probe were passed through the 19-gauge EUS needle in two patients with a PCL in the head of the pancreas and successfully yielded histology for two PCLs. Currently, novel devices like TTTN Moray microforceps have been developed, and some authors have confirmed in different report cases that it can be useful in determination of histology of PCLs [10-12]. However, experience with EUSTTNB for PCLs is still limited, and accordingly, we carried out a systematic review to evaluate the safety and efficacy of this new technique.

\section{Patients and methods}

\section{Literature search}

We performed a systematic review on PubMed, OVID Medline, and Cochrane Databases, by searching for studies published up to October 2019. The search was limited to English-language and human studies, and it was carried out using the following entries: "endoscopic ultrasound," "through-the-needle microforceps biopsy," "Moray microforceps," "pancreatic cystic lesions," "pancreatic cystic neoplasms," and "EUS-guided microbiopsy. Boolean operators (NOT, AND, OR) were also used in succession to narrow and widen the search. Only publications on EUS-TTNB in PCLs were considered, whereas studies with only other cystic evaluations without microforceps biopsy, individual or multiple report cases, duplicates and those with redundant data, review articles or book chapters, commentaries or editorials, non-relevant publications, and alternative tech-

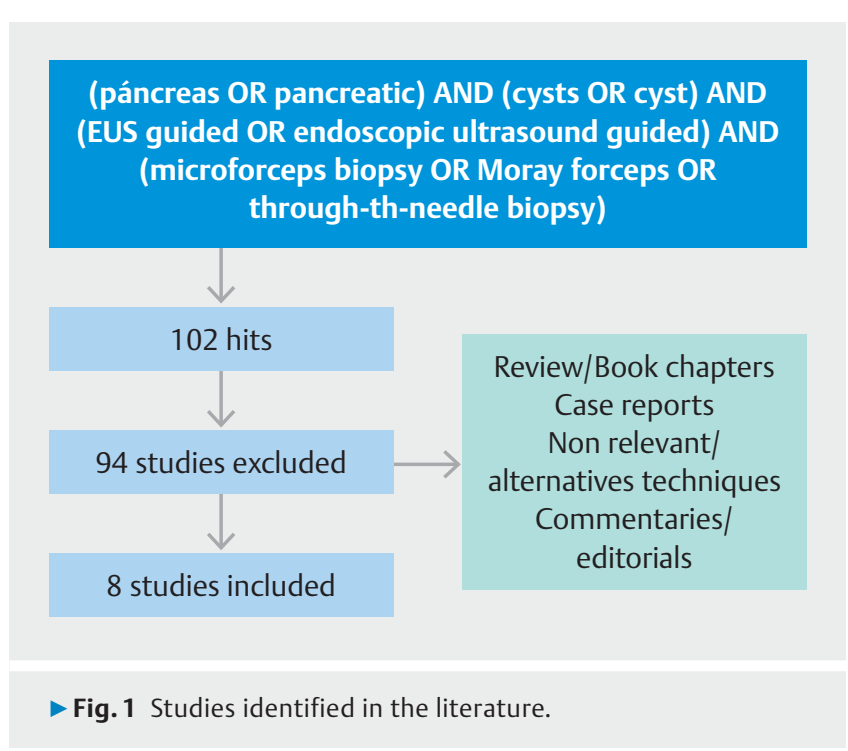

niques of fluid cystic analyses, were excluded and not considered for the present pooled-data analysis ( $>$ Fig. 1). There was $100 \%$ concordance between reviewers for study selection and data abstraction.

\section{Endpoints}

Rates of technical success, adequate specimens, adverse events (AEs), and overall diagnosis were computed. We defined technical success as successful puncture of the pancreatic cyst, subsequent successful mounting of the microbiopsy forceps, and extraction of at least one microbiopsy. The reference standard for overall diagnosis was surgical histopathology in most cases. Adequate specimens were defined as procurement of useful histological results and if the microforceps could be passed through the needle inside the cyst where the jaws of the microforceps were opened and closed to perform the biopsy. Procedure-related AEs were recorded: abdominal pain, fever, acute pancreatitis, extracystic bleeding, and infection. AEs were stratified based in ASGE classification based mainly on need for hospitalization: Mild, events requiring hospitalization of 1 to 3 days; moderate, 4 to 9 days in hospital; severe, more than 10 days in the hospital or needing surgery or intensive care; fatal, death attributable to the procedure [13].

\section{Data extraction}

Full texts of all selected articles were reviewed to confirm study eligibility. A data extraction form was developed in advance to extract the following information from each study: first author, year of publication, study design, number of patients enrolled, age, gender, PCLs characteristics (site of the lesion, type of the lesion, mean size, multifocality, wall of the lesions), technical success, adequate specimens, adverse events and overall histological diagnosis of pancreatic cysts.

\section{Data analysis}

The percentages and their $95 \%$ confidence intervals (Cls) were calculated for all the considered endpoints. (technical success rate, adverse events rate and overall diagnosis rate). The Green- 
wood method was used. The Statistical Package for Social Sciences for Windows version 22 (SPSS Inc. Chicago, Illinois, United States) was used to analyze the data.

\section{Results}

A flow diagram depicting the search and selection process is provided in $>$ Fig. 1. The initial search yielded 102 articles of which eight studies were finally analyzed [14-21].

\section{Characteristics of included studies}

Characteristics of the eight included studies are listed in $>\mathbf{T a}$ ble 1 [14-21]. These studies, comprising 423 patients, were published between 2018 and 2019. Six studies were retrospective and of them, fou rwere multicenter; one was prospective and one was cohort study in design. There were no randomized controlled trials. Mean age of patients ranged from 50.2 to 69.6 years. Of the 423 patients, 172 were male (40.6\%) and 251 were female (59.4\%).

\section{PCL characteristics}

$\mathrm{PCL}$ characteristics are shown in $>$ Table 1 . Cysts were located in the head of the pancreas (neck and uncinate were included) in 163 patients (38.5\%), in the body in 142 (33.5\%), and in the tail in $101(23.8 \%)$. Thirteen cysts (3,.\%), were located in the body and/or tail in the study by Mittal et al [18], without specifying the exact location and no location was specified for four cysts $(0.9 \%)$ in the study by Yang et al [20].

Mean size of cysts was $34.0 \mathrm{~mm}$ (mean size ranging of 28.2$40.7 \mathrm{~mm}$ ). Only five studies specified whether the lesion was uniloculart $[13-15,18,19]$. In 167 cases $(39.4 \%)$, cysts were uniloculated whereas in 147 cases (34.7\%), they were reported as multiloculated or septated; the remainder were not described. A mural nodule was reported in five studies [14-16, 19,20 ], in total 28 cases (6.6\%) of mural nodules were reported in the different studies.

\section{Technical successful rates}

Mean technical success rate in the different studies ranged from $85.7 \%$ to $100 \%$. In all eight studies, pooled technical success was reported in $95.6 \%$ of cases (399/423), with a $95 \%$ confidence interval $(\mathrm{Cl}) 93.2 \%$ to $97.3 \%$ ( $\mathbf{F i g . 2}$ ). The technical failure rate was reported in 24 cases (5.1\%). Frequency of adequate specimens was $82.2 \%$, $(95 \% \mathrm{Cl}, 78.5 \%-85.8 \%)$ reported in seven of eight studies, (mean rate $71.4 \%-91.6 \%$ ).

\section{Adverse events}

AEs were reported in seven of eight studies. Forty-two total AEs occurred in 375 patients (10.1\% of total cases) $(95 \% \mathrm{Cl}, 7.3 \%-$ $13.6 \%$ ) ( Fig. 3). In two studies [18, 19], there were no AEs. No comment was made about AEs in one study [21]. In 39 patients, AEs were recorded as mild and in three as moderate. No severe or fatal AEs were observed ( $\triangleright$ Table 2 ).

Overall, of 39 mild adverse events occurred: 20 cases (51.2\%) of intracystic bleeding, 8 cases (20.5\%) of abdominal pain, 7 cases $(17.9 \%)$ of mild acute pancreatitis, 1 case $(2.5 \%)$ of abdominal pain plus intracystic bleeding, 1 case $(2.5 \%)$ of tran- sitory fever, 1 case (2.5\%) of peripancreatic bleeding, 1 case (2.5\%) of sinus bradycardia. All 3 cases of moderate adverse events were mild acute pancreatitis. In the study of Yang et al. [20], one patient developed a pseudocyst several weeks later that required endoscopic drainage, the patient recovered after stent removal without recurrence.

\section{Overall diagnoses}

The overall ability to provide a specific diagnosis with EUS-TTNB for diagnosis of pancreatic cystic lesions in all studies was $74.6 \%$ (313 of the 423 cases), $95 \% \mathrm{Cl}: 70.2 \%-78.7 \%$. Mean accuracy among studies ranged from $35.7 \%$ to $88.9 \%$ ( $>$ Fig. 4 ).

The most frequent diagnoses found with EUS-TTNB were: MCN in 96 cases (30.6\%), intraductal papillary mucinous neoplasm in 80 cases $(25.5 \%$ ), and SCN in 48 cases (15.3\%). In $>$ Table 3 and $>$ Table 4, detailed diagnoses obtained by EUS-TTNB in all the studies are reported.

\section{Discussion}

It has been acknowledged that some patients with PCLs have a significantly higher overall risk of pancreatic cancer [22], and actually, the frequent use of high-quality cross-sectional imaging has led to a significant rise in diagnosis of PCLs. In the meta-analysis of Zerboni G, et al in 2019, prevalence of PCLs in asymptomatic individuals was $8 \%$ [23], while incidence of these lesions increases with age and reaches $37 \%$ in patients older than 80 [24]. In Spain, a prospective study performed in 298 patients, the authors recorded that incidental prevalence of pancreatic cysts on EUS (21.5\%) was higher than prevalence estimates in cross-sectional imaging studies [6]. Surgery is currently considered the standard of care for malignant and highrisk premalignant PCLs. At present, the great problem is optimization of diagnostic tools, and given their accuracy, patients may be overtreated with surgery, or to the contrary, may not be kept under surveillance when they should be. Actually, EUSTTNB is a technique that allows targeted tissue acquisition of the PCLs. We performed a systematic review literature with pooled data analysis of available studies to evaluate performance of EUS-TTNB for diagnosis of pancreatic cystic lesions.

All authors used a standard technique. An oblique/forwardviewing therapeutic linear array echoendoscope was used to visualize the PCLs. The cyst was then punctured by using a 19gauge EUS-FNA needle, with a stylet. A transgastric or trasduodenal approach was used for PCLs, the stylet was removed, and a biopsy of the wall of the cyst was done by using the microforceps passed through the 19-gauge needle under direct EUS visualization. The open jaws of the forceps were pushed onto the cyst wall, closed and pulled back to cause visible tenting. The forceps were then "plucked" and removed from the patient, leaving the 19-gauge needle in the cyst. Crino et al. [16], found that a mean number of 3.25 passes per patient was necessary to obtain 3 visible histologic specimens, which were judged to be adequate for histologic evaluation in approximately $92 \%$ and performed one "bite" per pass from observing the "tent sign" of the cystic wall, which theoretically demonstrates an effective grip of the microforceps on the wall. With the protocol of Crino 


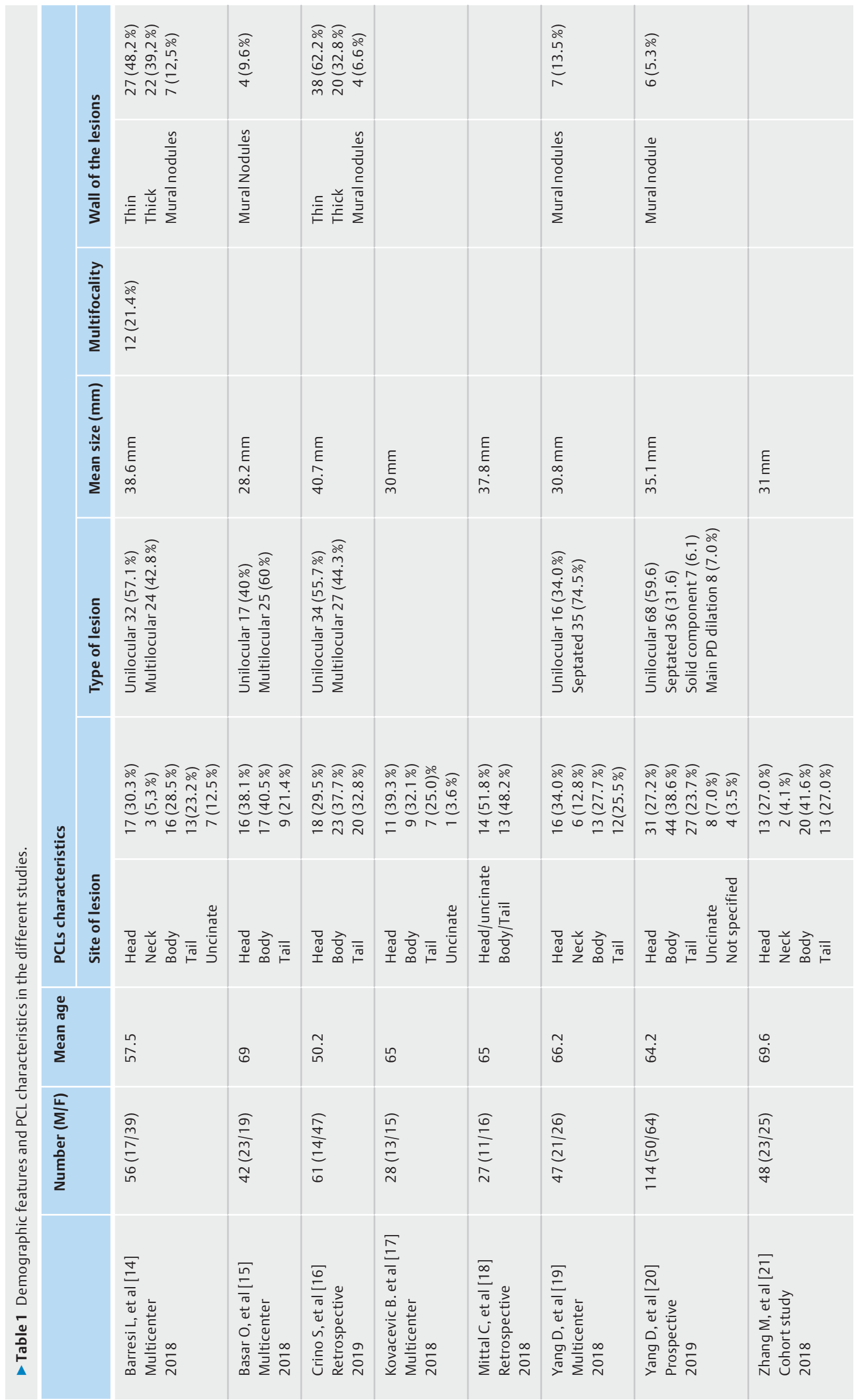




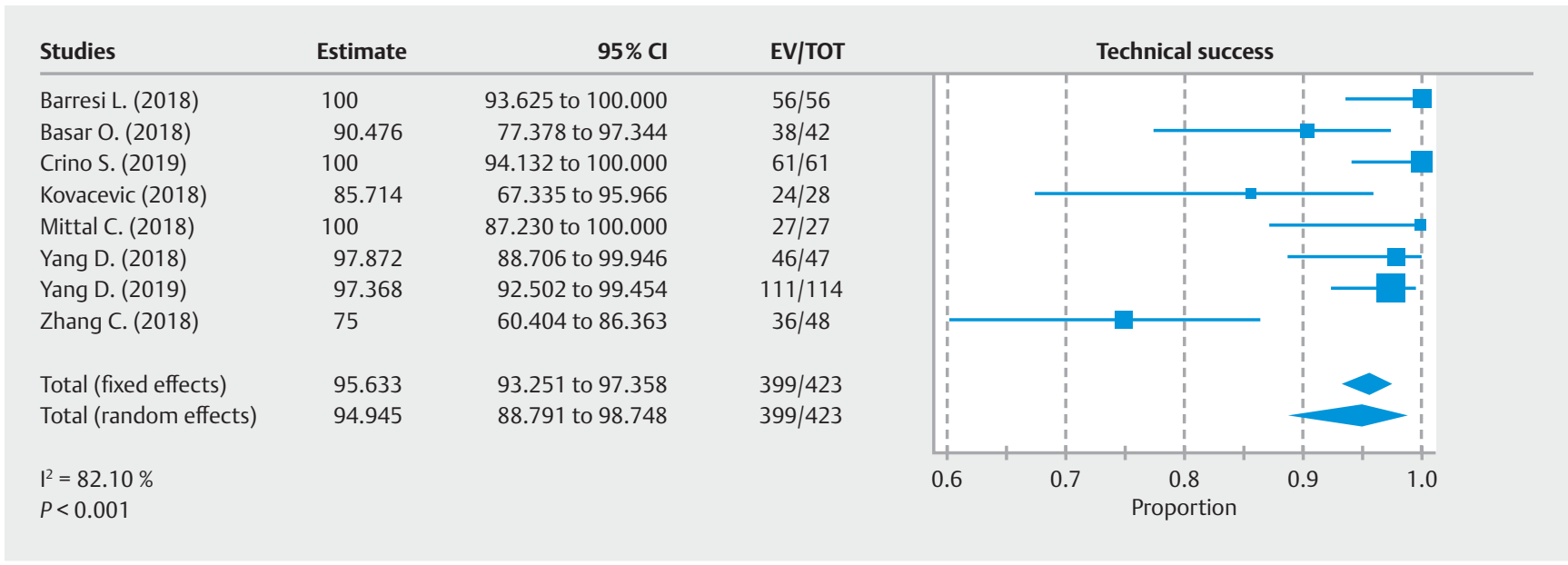

- Fig. 2 Pooled analysis assessing rates of technical success of microforceps biopsy in targeting pancreatic cyst lesions. Technical success in targeting pancreatic cysts was $95.6 \%(93.2 \%-97.3 \% ; 12=82.1 \%)$.

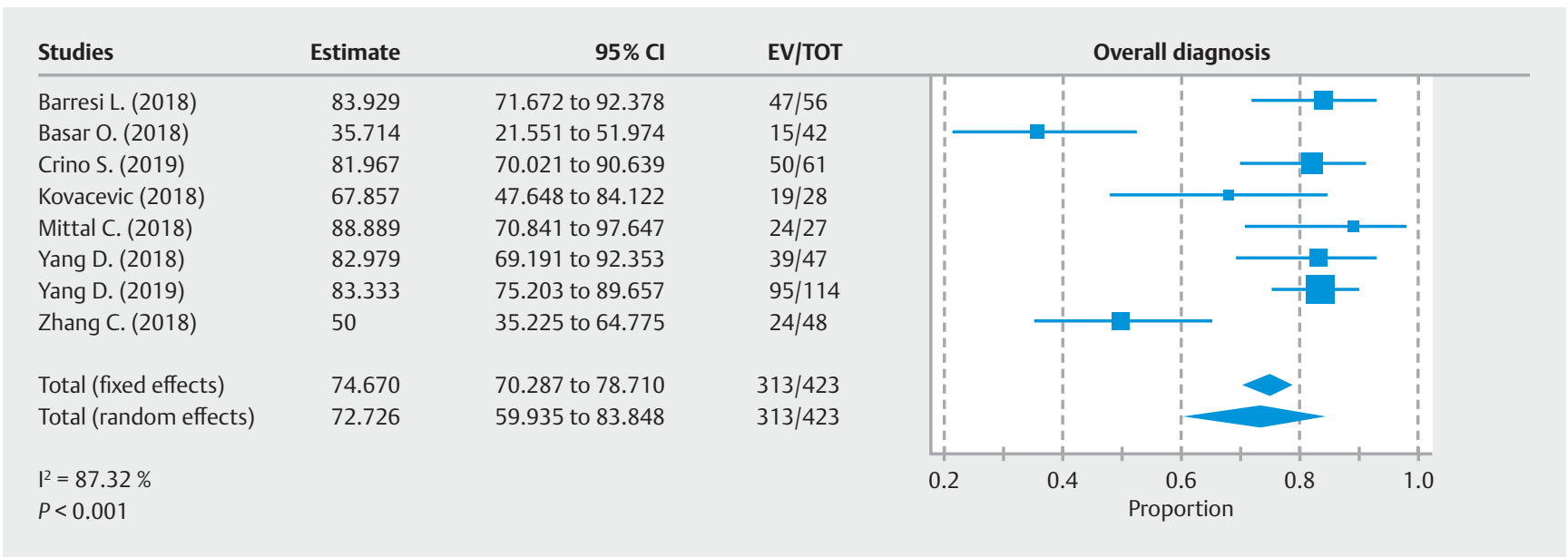

- Fig. 3 Pooled analysis assessing rates of overall diagnosis of microforceps biopsy in targeting pancreatic cyst lesions. Overall diagnosis in targeting pancreatic cysts was $74.6 \%(70.2 \%-78.7 \% ; 12=87.3 \%)$.

et al, they reached $100 \%$ histologic adequacy after two biopsy samples. Yang et al [19], performed three bites per pass for a total of three passes, obtaining a histologic sample in only $83 \%$ of the cases.

Since the first case reported by Aparicio et al, [9] in 2010, many case reports have been published [11,25-30]. We collected data from eight studies, with the first published in 2018 , overall including 423 patients. In this systematic review, we have observed a predominance of PCLs in women, in seven of eight studies, (ratio F:M of 1.5:1) whereas the mean age of patients was 63.3 years and was similar in different series (ranging from 50.2 to 69.6 years). The site of the PCLs was distributed differently and heterogeneously in the different studies, however, pooled analysis data show that the most frequent location was in the head of the pancreas (38.5\%). In our analysis, pancreatic neck and uncinated process were included in this group, because some authors do not discriminate or differentiate between these locations individually. Only Barresi L et al [14] no- ted distribution of lesions in five regions (head, neck, body, tail and uncinated).

Lesion type was reported in five of eight studies [14-16, 19, 20], with unilocular being the most frequently reported (39.4\%). In three studies, $[15,16,19]$, no statistically significant relationship was found between cyst features or biopsy sampling route and the diagnostic yield of two TTNB-EUS specimens, except for a lower capability to retrieve the cyst epithelial lining in lesions located in the pancreatic tail. Mean size of PCLs was $34.0 \mathrm{~mm}$ and was similar in different series (ranging from 28.2 to $40.7 \mathrm{~mm}$ ). Only Barresi L et al [14] reported 12 cases (21.4\%) of multifocality of cysts in their study.

According to the recent European guidelines [5], presence of an enhancing mural nodule $(\geq 5 \mathrm{~mm})$ is an absolute indication for surgery; patients with mucinous cystic neoplasm $\geq 40 \mathrm{~mm}$ should undergo surgical resection if a mural nodule exists irrespective of their size $[5,30]$. In this systematic review, we found that five of eight studies recorded presence of the mural nodule 
- Table 2 Results of and adverse events from endoscopic ultrasound-guided through-the-needle forceps biopsy.

\begin{tabular}{|c|c|c|c|}
\hline Study & Technical success rate & Specimen adequacy & Adverse events \\
\hline Barresi L et al [14] & $56(100 \%)$ & $47(83.9 \%)$ & $\begin{array}{l}\text { Total } 9(16 \%) \\
\text { Grade: } \\
\text { Mild: } 9 \\
\text { Type of adverse event } \\
\text { Abdominal pain: } 7 \\
\text { Intracystic hemorrage: } 3\end{array}$ \\
\hline Basar O et al [15] & $38(90.4 \%)$ & $30(71.4 \%)$ & $\begin{array}{l}\text { Total } 2(4,7 \%) \\
\text { Grade: } \\
\text { Mild: } 2 \\
\text { Type of adverse event } \\
\text { Abdominal pain: } 1 \\
\text { Intracystic hemorrage: } 1\end{array}$ \\
\hline Crino $S$ et al [16] & $61(100 \%)$ & $91.6 \% *$ & $\begin{array}{l}\text { Total } 14(22.9 \%) \\
\text { Grade: } \\
\text { Mild: } 14 \\
\text { Type of adverse event } \\
\text { Transitory fever: } 1 \\
\text { Intracystic hemorrage: } 10 \\
\text { Mild acute pancreatitis: } 2 \\
\text { Peripancreatic bleeding: } 1\end{array}$ \\
\hline Kovacevic B et al [17] & $24(85.7 \%)$ & $20(71.4 \%)$ & $\begin{array}{l}\text { Total } 3(10.7 \%) \\
\text { Grade: } \\
\text { Mild: } 1 \\
\text { Moderate: } 2 \\
\text { Type of adverse event } \\
\text { Abdominal pain: } 1 \\
\text { Intracystic hemorrage: } 0 \\
\text { Mild acute pancreatitis: } 2\end{array}$ \\
\hline Mittal C et al [18] & $27(100 \%)$ & $24(88.9 \%)$ & Total: $0(0 \%)$ \\
\hline Yang D et al [19] & $46(97.9 \%)$ & $40(85.1 \%)$ & Total: $0(0 \%)$ \\
\hline Yang D et al [20] & $111(97.4 \%)$ & $95(83.3 \%)$ & $\begin{array}{l}\text { Total } 14(12.3 \%) \\
\text { Grade: } \\
\text { Mild: } 13 \\
\text { Moderate: } 1 \\
\text { Type of adverse event } \\
\text { Intracystic hemorrage: } 7 \\
\text { Mild acute pancreatitis: } 6 \\
\text { Sinus bradycardia: } 1 \\
\text { Pseudocyst: } 1\end{array}$ \\
\hline Zhang M et al [21] & $36(75 \%)$ & & No reported \\
\hline
\end{tabular}

$[14-16,19,20]$, in total, 28 cases of mural nodule were reported.

Timing of the procedures was assessed only in the study by Kovacevic et al [17], they reported a mean procedural time of 32 minutes, with a mean of three biopsy samplings performed.

In all eight studies, encouraging results were reported in terms of both technical success and diagnostic yield. The technical success rate was $95.6 \%$ (399 of 423 cases), with a mean technical success rate ranging from $85.7 \%$ to $100 \%$ in the different studies, whereas the technical failure rate was reported in 24 cases (5.1\%). The overall ability to provide a specific diagnosis with EUS-TTNB for diagnosis of pancreatic cystic lesions in all studies was $74.6 \%$ (313 of 423 cases). The mean rate ranged from $35.7 \%$ to $88.9 \%$. However, the arguments to explain the advantage of TTNB on cytology are also problems for TTNB (heterogeneity of presence of epithelium in mucinous cystic neoplasm, IPMN or neuroendocrine neoplasm) and one limit of TTNB is inability to check a large part of the wall. That is may explain why diagnosis with TTNB, overall, is imperfect.

Technical failure seems to be caused by loss of flexibility of the echoendoscope when both forceps and the FNA needle are inserted. Other technical difficulties described did not hinder procurement of specimens. Failures were seen in locations where EUS-guided puncture is known to be challenging, i.e., when the echoendoscope was placed in the duodenum [16]. In the study by Barresi et al [14], specimens were considered adequate for histological diagnosis in 47 of 56 (83.9\%; $95 \% \mathrm{Cl}$, $72 \%-92 \%)$. In two of these patients, despite histological ade- 


\section{Studies}

Barresi L. (2018)

Basar O. (2018)

Crino S. (2019)

Kovacevic (2018)

Mittal C. (2018)

Yang D. (2018)

Yang D. (2019)

Total (fixed effects)

Total (random effects)

$\mathrm{I}^{2}=80.13 \%$

$P<0.001$
$95 \% \mathrm{Cl}$

7.622 to 28.328

0.582 to 16.164

13.153 to 35.498

2.267 to 28.226

0 to 12.770

0 to 7.549

6.879 to 19.746

7.304 to 13.618

3.320 to 16.326
EV/TOT

\section{9/56}

2/42

$14 / 61$

$3 / 28$

$0 / 27$

$0 / 47$

$14 / 114$

$42 / 375$

$42 / 375$

10.144

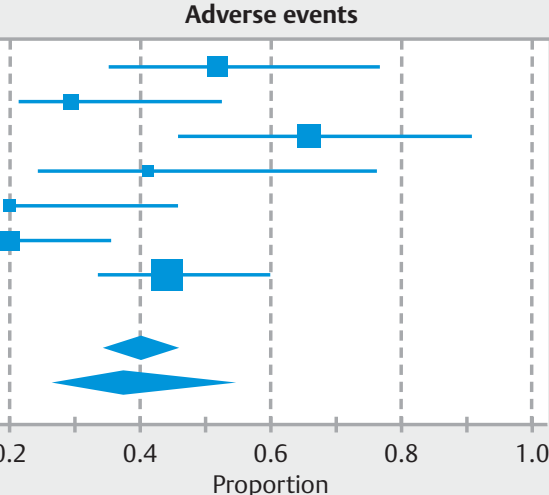

- Fig. 4 Pooled analysis assessing rates of adverse events of microforceps biopsy in targeting pancreatic cyst lesions. Overall diagnosis in targeting pancreatic cysts was $10.1 \%(7.3 \%-13.6 \%$; $12=80.13 \%)$

- Table 3 EUS-TTNB diagnosis in different studies.

\begin{tabular}{|c|c|c|c|}
\hline Study & Overall diagnosis & EUS TTNB diagnosis & \\
\hline \multirow[t]{7}{*}{ Barresi L et al [14] } & \multirow[t]{7}{*}{$47(83.9 \%)$} & Serous cystoadenoma & $14(29.7 \%)$ \\
\hline & & BD-IPMN & $10(21.2 \%)$ \\
\hline & & Cystic mucinous neoplasm & $8(17 \%)$ \\
\hline & & Pseudocyst & $7(14.8 \%)$ \\
\hline & & No definite mucinous cyst & $4(8.5 \%)$ \\
\hline & & Malignant cystic neoplasm & $3(6.3 \%)$ \\
\hline & & Other & $1(2.1 \%)$ \\
\hline \multirow[t]{6}{*}{ Basar O. et al [15] } & \multirow[t]{6}{*}{$15(35.7 \%)$} & Serous cystoadenoma & $3(20 \%)$ \\
\hline & & BD-IPMN & $6(40 \%)$ \\
\hline & & Cystic mucinous neoplasm & $2(13.3 \%)$ \\
\hline & & Adenocarcinoma & $2(13.3 \%)$ \\
\hline & & CPNET & $1(6.6 \%)$ \\
\hline & & Acinar cystoadenoma & $1(6.6 \%)$ \\
\hline \multirow[t]{11}{*}{ Crino $S$ et al [16] } & \multirow[t]{11}{*}{$50(81.9 \%)$} & Serous cystoadenoma & $13(21.3 \%)$ \\
\hline & & BD-IPMN & $7(11.5 \%)$ \\
\hline & & Cystic mucinous neoplasm & $14(22.9 \%)$ \\
\hline & & Pseudocyst & $2(3.3 \%)$ \\
\hline & & Neuroendocrine tumors & $5(8.2 \%)$ \\
\hline & & Squamoid cyst & $3(4.9 \%)$ \\
\hline & & Lymphangioma & $2(3.3 \%)$ \\
\hline & & Mucinous non-neoplastic cyst & $2(3.3 \%)$ \\
\hline & & Lymphoepithelial cyst & $1(1.6 \%)$ \\
\hline & & Solid pseudopapillary neoplasm & $1(1.6 \%)$ \\
\hline & & No definite & $11(18 \%)$ \\
\hline
\end{tabular}


- Table 3 (Continuation)

\begin{tabular}{|c|c|c|c|}
\hline Study & Overall diagnosis & EUS TTNB diagnosis & \\
\hline \multirow[t]{8}{*}{ Kovacevic B et al [17] } & \multirow[t]{8}{*}{19 of 24 (79.1\%) } & Serous Cystoadenoma & $2(8.3 \%)$ \\
\hline & & BD-IPMN & $13(54.1 \%)$ \\
\hline & & Cystic mucinous neoplasm & $1(4.2 \%)$ \\
\hline & & Pseudocyst & $1(4.2 \%)$ \\
\hline & & Neuroendocrine tumors & $2(8.3 \%)$ \\
\hline & & MCN associated carcinoma & $1(4.2 \%)$ \\
\hline & & Insufficient material & $1(4.2 \%)$ \\
\hline & & Inconclusive & $3(12.5 \%)$ \\
\hline \multirow[t]{5}{*}{ Mittal C et al [18] } & \multirow[t]{5}{*}{$24(88.9 \%)$} & Serous cystoadenoma & $4(14.8 \%)$ \\
\hline & & BD-IPMN & $0(0 \%)$ \\
\hline & & Cystic mucinous neoplasm & $9(33.3 \%)$ \\
\hline & & Benign / Inflammatory & $10(37.1 \%)$ \\
\hline & & Neuroendocrine tumors & $1(3.7 \%)$ \\
\hline \multirow[t]{4}{*}{ Yang D et al [19] } & \multirow[t]{4}{*}{$39(82.9 \%)$} & Serous cystoadenoma & $4(8.5 \%)$ \\
\hline & & Cystic mucinous neoplasm & $26(55.3 \%)$ \\
\hline & & Benign fibrous tissue & $7(14.9 \%)$ \\
\hline & & Inflammatory cells & $2(4.2 \%)$ \\
\hline \multirow[t]{7}{*}{ Yang D et al [20] } & \multirow[t]{7}{*}{$95(88.9 \%)$} & Serous cystoadenoma & $5(4.3 \%)$ \\
\hline & & Mucinous cyst & $61(53.5 \%)$ \\
\hline & & Mucinous cyst with adenocarcinoma & $2(1.7 \%)$ \\
\hline & & Inflammatory & $14(12.2 \%)$ \\
\hline & & Benign glandular cells & $6(5.2 \%)$ \\
\hline & & Solid pseudopapillary tumor & $1(0.8 \%)$ \\
\hline & & Cystic neuroendocrine tumor & $6(5.2 \%)$ \\
\hline \multirow[t]{5}{*}{ Zhang M et al [21] } & \multirow[t]{5}{*}{$24(50 \%)$} & Serous cstoadenoma & $3(6.3 \%)$ \\
\hline & & BD-IPMN & $18(37.5 \%)$ \\
\hline & & Mucinous cystic neoplasm & $1(2.1 \%)$ \\
\hline & & Adenocarcinoma & $1(2.1 \%)$ \\
\hline & & Acinar cystoadenoma & $1(2.1 \%)$ \\
\hline
\end{tabular}

quacy, a diagnosis could not be reached. In the other two cases, a specimen sufficient for cytological diagnosis was obtained. Basar et al [15] reported that pinch biopsy specimen was insufficient for histology processing in four of 42 patients (9.6\%), two from a cyst wall and two from a septum. Crino et al [16], reported that inadequacy was because of clots in 10 cases and amorphous material in five cases. Mittal et al [18] no reported procedural difficulty, but microforceps biopsies did not provide a pathologic diagnosis in three cases because tissue obtained with the microforceps biopsy was not adequate for pathologic diagnosis. Kovacevic et al [17] reported technical failure in four patients, due to inability to access the cyst while the echoendoscope was maximally flexed, and observation of lesions located in the head ( 3 cases) and the tail ( 1 case) of the pancreas, the latter with failed transgastric puncture.

The most frequent diagnoses found with EUS-TTNB were: mucinous cystic neoplasms in 96 cases (30.6\%), IPMN in 80 cases $(25.5 \%)$, and serous cystoadenoma neoplasm in 48 cases (15.3\%). Distinguishing between a serous and mucinous cystic neoplasm is important because all mucinous cystic neoplasms 
Table4 Overall diagnosis of PCLs in studies of EUS-TTNB.

\begin{tabular}{|c|c|c|c|c|c|c|c|c|c|c|}
\hline Diagnosis & $\begin{array}{l}\text { Barresi } \\
\text { L, et al } \\
{[13]}\end{array}$ & $\begin{array}{l}\text { Basar } \\
\text { O, et } \\
\text { al [14] }\end{array}$ & $\begin{array}{l}\text { Crino } \\
\text { S, et al } \\
{[15]}\end{array}$ & $\begin{array}{l}\text { Kovace- } \\
\text { vic B. et } \\
\text { al [16] }\end{array}$ & $\begin{array}{l}\text { Mittal } \\
\text { C, et al } \\
{[17]}\end{array}$ & $\begin{array}{l}\text { Yang } \\
\text { D, et } \\
\text { al [18] }\end{array}$ & $\begin{array}{l}\text { Yang } \\
\text { D, et } \\
\text { al [19] }\end{array}$ & $\begin{array}{l}\text { Zhang } \\
\text { M, et al } \\
{[20]}\end{array}$ & Total & $\%$ \\
\hline Serous cystoadenoma neoplasm & 14 & 3 & 13 & 2 & 4 & 4 & 5 & 3 & 48 & 15.34 \\
\hline IPMN & 10 & 6 & 7 & 13 & & 26 & & 18 & 80 & 25.56 \\
\hline Mucinous cystic neoplasm & 8 & 2 & 14 & 1 & 9 & & 61 & 1 & 96 & 30.67 \\
\hline Pseudocyst & 7 & & 2 & 1 & & & & & 9 & 2.88 \\
\hline Malignant cystic neoplasm & 3 & & & 1 & & & 2 & & 6 & 1.92 \\
\hline Adenocarcinoma & & 2 & & 1 & & & 2 & 1 & 3 & 0.96 \\
\hline Neuroendocrine pancreatic tumor & & 1 & 5 & 2 & 1 & & 6 & & 15 & 4.79 \\
\hline Acinar cystoadenoma & & 1 & & & & & & 1 & 2 & 0.64 \\
\hline Squamoid cyst & & & 3 & & & & & & 3 & 0.96 \\
\hline Lymphangioma & & & 2 & & & & & & 2 & 0.64 \\
\hline Mucinous non-neoplastic cyst & & & 2 & & & & & & 2 & 0.64 \\
\hline Lymphoephitelial cyst & & & 1 & & & & & & 1 & 0.32 \\
\hline Solid pseudopapillary Neoplasm & & & 1 & & & & 1 & & 2 & 0.64 \\
\hline No definite mucinous cyst & 4 & & & & & & & & 4 & 1.28 \\
\hline Benign/inflammatory & & & & & 10 & 9 & 20 & & 39 & 12.46 \\
\hline Other & 1 & & & & & & & & 1 & 0.32 \\
\hline No definite diagnosis & & & 11 & 3 & & & & & 14 & 4.47 \\
\hline Total & 47 & 15 & 50 & 19 & 24 & 39 & 95 & 24 & 313 & 100 \\
\hline
\end{tabular}

PCL, pancreatic cystic lesion; EUS-TTNB, endoscopic ultrasound-guided through-through-needle forceps biopsy; IPMN, intraductal papillary mucinous neoplasm.

are resected regardless of grade because of the ease of the usual distal pancreatectomy compared with the expense and anxiety of life-long surveillance for progression to malignancy in the typical middle-aged woman [31]. Conversely, branch duct IPMNs without high-risk features behave in a benign fashion and occur mostly in elderly patients, thereby supporting a conservative management approach [21]. Therefore, determining cyst type as well as the malignant potential of a cyst dictates the best treatment strategy while avoiding unnecessary surgery. Furthermore, TTNB has advantages over cytology alone, the latter is insufficient for diagnosis in up to $60 \%$ of patients because of the absence of epithelial cells in cyst fluid, presence of gastrointestinal contamination, heterogeneity of mucinous cyst dysplasia, and lack of experience and expertise in cytologic interpretation [32-35]. In addition, the fragile cells of serous cystadenoma rarely survive processing for diagnosis, and the subepithelial ovarian-type stroma required for diagnosis of MCN is not present in aspirated cyst fluid. Conversely, TTNB provides tissue from the cyst wall, septations, and mural nodules for histology, thus providing tissue for ancillary studies such as immunohistochemistry, and the distinction between these two types of mucinous cysts was only possible with the addition of TTNB. It would be interesting to study whether TTNB can be useful for diagnosing the histological type of
IPMN, but none of the eight studies mention it. In conclusion, our systematic review showed that the effectivenes of TTNBEUS was not affected by size, location, or septations in cysts and provided a specific diagnosis for the subtype of pancreatic cyst.

Forty-two total AEs in 375 patients ( $10.1 \%$ of total cases), 39 patients were recorded as mild AEs and three as moderate AEs. No severe or fatal AEs were observed. Barresi et al [14] reported that intracystic bleeding from the sites of micro-biopsy in the cystic wall was the most common AE observed, and was selflimited in all cases. Basar et al [15], do not observed serious AEs. Only one patient had mild abdominal pain, which lasted for an hour after the procedure. Another patient had self-limited intracystic bleeding, which did not progress and did not result in any symptoms. Crino et al [16] observed a case of transitory fever with possible cyst infection, which resolved with conservative treatment without the need for hospital admission. In this cohort, they observed an overall AEs rate of $22.9 \%$, with a slight increase in intracystic bleeding (16.4\%). In all cases, bleeding was self-limiting and asymptomatic and did not require medical intervention. Three moderate AEs were recorded, two by Kovacevic et al [17] and one by Yang et al [20]. All were mild acute pancreatitis. Two patients were hospitalized for 4 and 6 days, respectively. They were treated with intravenous 
fluids and analgesics and recovered completely [17]. Yang et al [20] reported six patients with postprocedural acute pancreatitis based on laboratories and imaging, and abdominal pain within 12 to 24 hours after the EUS, nearly all of these episodes were mild ( 5 of 6 ); three patients required hospitalization. Two of these patients were discharged within 24 to 48 hours with supportive care and subsequently followed up in the clinic without any sequelae. One patient developed a pseudocyst several weeks later that required endoscopic drainage. The patient recovered after stent removal without recurrence. Limitations of our study, are mainly based on the fact that unfortunate issues with study centers handing out data to multiple studies, hence, a systemic review or meta-analysis is never accurate unless the authors disclose the data and account for redundancy from each of these study centers.

The current status of new technologies for evaluation of PCLs includes confocal endomicroscopy and molecular markers. Both EUS-nCLE and cyst fluid molecular analysis of PCLs represent promising new modalities to improve the diagnostic evaluation of PCLs. EUS with nCLE identified mucinous PCLs with $98 \%$ sensitivity, $94 \%$ specificity, and $97 \%$ accuracy. nCLE was more accurate in classifying mucinous vs nonmucinous cysts than the standard method. In clinical practice, these technologies may be particularly useful in cases with diagnostic uncertainty so as to improve accuracy and allow for appropriate risk stratification [1].

\section{Conclusion}

In our systematic review, we observed that TTNB appears to be effective and safe, with few AEs for diagnosis of pancreatic cystic lesions. The technique had acceptable rates of technical and clinical success and an excellent safety profile. TTNB is associated with a high tissue acquisition yield and provided additional diagnostic yield for mucinous pancreatic lesions. We think that TTNB may be a useful adjunctive tool for EUS-guided assessment of PCLs, complementing existing EUS-FNA sampling protocols. Future prospective studies and randomized controlled trials are needed to further validate our initial findings and the type of cysts in which this procedure should be performed.

\section{Competing interests}

The authors declare that they have no conflict of interest.

\section{References}

[1] Li F, Malli A, Cruz-Monserrate Z et al. Confocal endomicroscopy and cyst fluid molecular analysis: comprehensive evaluation of pancreatic cysts. World J Gastrointest Endosc 2018; 10: 1-9

[2] Jana T, Shroff J, Bhutani MS. Pancreatic cystic neoplasms: review of current knowledge, diagnostic challenges, and management options. J Carcinog 2015; 14: 3

[3] Kohoutova D, Zar S, Repak R et al. Pancreatic cysts: diagnostic role of eus-guided microforceps biopsy and confocal laser endomicroscopy.
Gastroenterol Res Pract 2019; 2019: 3431048 (Published online 2019 Sept 12)

[4] Del Chiaro M, Verbeke C, Salvia R et al. European experts consensus statement on cystic tumours of the pancreas. Dig Liver Dis 2013; 45: 703-711

[5] European Study Group on Cystic Tumours of the Pancreas. European evidence-based guidelines on pancreatic cystic neoplasms. Gut 2018; 67: 789-804

[6] Martínez B, Martínez JF, Aparicio JR. Prevalence of incidental pancreatic cyst on upper endoscopic ultrasound. Ann Gastroenterol 2018; 31: $90-95$

[7] Gillis A, Cipollone I, Cousins G et al. Does EUS-FNA molecular analysis carry additional value when compared to cytology in the diagnosis of pancreatic cystic neoplasm? A systematic review HPB (Oxford) 2015; 17: 377-386

[8] Krishna SG, Hart PA, Malli A et al. Endoscopic ultrasound-guided confocal laser endomicroscopy increases accuracy of differentiation of pancreatic cystic lesions. Clin Gastroenterol Hepatol 2020; 18: 432$440 \mathrm{e} 6$

[9] Aparicio JR, Martínez J, Niveiro M et al. Direct intracystic biopsy and pancreatic cystoscopy through a 19-gauge needle EUS (with videos). Gastrointest Endosc 2010; 72: 1285-1288

[10] Shakhatreh M, Naini S, Brijbassie A et al. Use of a novel through-theneedle biopsy forceps in endoscopic ultrasound. Endosc Int Open 2016; 4: E439-E442

[11] Attili F, Pagliari D, Rimba M. Endoscopic ultrasound-guided histological diagnosis of a mucinous non-neoplastic pancreatic cyst using a specially designed through-the-needle microforceps. Endoscopy 2016; 48: E188-E189

[12] Huelsen A, Cooper C, Saad N et al. Endoscopic ultrasound-guided, through-the-needle forceps biopsy in the assessment of an incidental large pancreatic cystic lesion with prior inconclusive fine-needle aspiration. Endoscopy 2017; 49: E109-E110

[13] Cotton P, Eisen G, Aabakken L et al. A lexicon for endoscopic adverse events: report of an ASGE workshop. Gastrointest Endosc 2010; 71: 446-454

[14] Barresi L, Crinò SF, Fabbri C et al. Endoscopic ultrasound-through-theneedle biopsy in pancreatic cystic lesions: A multicenter study. Dig Endosc 2018; 30: 760-770

[15] Basar O, Yuksel O, Yang DJ et al. Feasibility and safety of microforceps biopsy in the diagnosis of pancreatic cysts. Gastrointest Endosc 2018; 88: 79-86

[16] Crinò S, Bernardoni L, Brozzi L et al. Association between macroscopically visible tissue samples and diagnostic accuracy of EUS-guided through-the-needle microforceps biopsy sampling of pancreatic cystic lesions. Gastrointest Endosc 2019; 90: 933-943

[17] Kovacevic B, Karstensen J, Havre R et al. Initial experience with EUSguided microbiopsy forceps in diagnosing pancreatic cystic lesions: A multicenter feasibility study (with video). Endosc Ultrasound 2018; 7: $383-388$

[18] Mittal C, Obuch J, Hammad $\mathrm{H}$ et al. Technical feasibility, diagnostic yield, and safety of microforceps biopsies during EUS evaluation of pancreatic cystic lesions (with video). Gastrointest Endosc 2018; 87: 1263-1269

[19] Yang D, Samarasena J, Jamil L et al. Endoscopic ultrasound-guided through-the-needle microforceps biopsy in the evaluation of pancreatic cystic lesions: a multicenter study. Endosc Int Open 2018; 6: E1423-E1430

[20] Yang D, Trindade A, Yachimski P et al. Histologic analysis of endoscopic ultrasound-guided through the needle microforceps biopsies accurately identifies mucinous pancreas cysts. Clin Gastroenterol Hepatol 2019; 17: 1587-1596 
[21] Zhang M, Arpin R, Brugge W et al. Moray micro forceps biopsy improves the diagnosis of specific pancreatic cysts. Cancer Cytopathol 2018; 126: 414-420

[22] Munigala S, Gelrud A, Agarwal B et al. Risk of pancreatic cancer in patients with pancreatic cyst. Gastrointest Endosc 2016; 84: 81-86

[23] Zerboni G, Signoretti M, Crippa S et al. Systematic review and metaanalysis: Prevalence of incidentally detected pancreatic cystic lesions in asymptomatic individuals. Pancreatology 2019; 19: 2-9

[24] Farrell J. Prevalence, diagnosis and management of pancreatic cystic neoplasms: current status and future directions. Gut Liver 2015; 9 : 571-589

[25] Barresi L, Tarantino I, Ligresti D et al. A new tissue acquisition technique in pancreatic cystic neoplasm: endoscopic ultrasound-guided through-the-needle forceps biopsy. Endoscopy 2015; 47: E297-E298

[26] Coman R, Schlachterman A, Esnakula A et al. EUS-guided, throughthe-needle forceps: clenching down the diagnosis. Gastrointest Endosc 2016; 84: 372-373

[27] Huelsen A, Cooper C, Saad N et al. Endoscopic ultrasound-guided, through-the-needle forceps biopsy in the assessment of an incidental large pancreatic cystic lesion with prior inconclusive fine-needle aspiration. Endoscopy 2017; 49: E109-E110

[28] Pham KD, Engjom T, Gjelberg Kollesete $\mathrm{H}$ et al. Diagnosis of a mucinous pancreatic cyst and resection of an intracystic nodule using a novel through-the-needle micro forceps. Endoscopy 2016; 48: E125E133
[29] Samarasena J, Nakai Y, Shinoura S et al. EUS-guided, through-theneedle forceps biopsy: a novel tissue acquisition technique. Gastrointest Endosc 2015; 81: 225-226

[30] Nilsson L, Keane M, Shamali A et al. Nature and management of pancreatic mucinous cystic neoplasm (MCN): a systematic review of the literature. Pancreatology 2016; 16: 1028-1036

[31] Pitman M, Brugge W, Warshaw A. The value of cyst fluid analysis in the pre-operative evaluation of pancreatic cysts. J Gastrointest Oncol 2011; 2: 195-198

[32] Cizginer S, Turner B, Bilge A et al. Cyst fluid carcinoembryonic antigen is an accurate diagnostic marker of pancreatic mucinous cysts. Pancreas 2011; 40: 1024-1028

[33] Zhan X, Wang B, Liu F et al. Cyst fluid carcino embryonic antigen concentration and cytology by endosonography-guided fine needle aspiration in predicting malignant pancreatic mucinous cystic neoplasms. J Dig Dis 2013; 14: 191-195

[34] Pitman MB, Genevay M, Yaeger K et al. High-grade atypical epithelial cells in pancreatic mucinous cysts are a more accurate predictor of malignancy than "positive" cytology. Cancer Cytopathol 2010; 118: 434-440

[35] Springer S, Wang Y, Dal Molin M et al. A combination of molecular markers and clinical features improve the classification of pancreatic cysts. Gastroenterology 2015; 149: 1501-1510 